\title{
NOTE \\ NOTE \\ Internal Medicine \\ Diagnostic utility of measuring serum amyloid A with a latex agglutination turbidimetric immunoassay in bovine mastitis: Comparison with haptoglobin and alpha 1 acid glycoprotein
}

\author{
Marina OTSUKA ${ }^{1)}$, Mieko SUGIYAMA ${ }^{2)}$, Takaaki ITO ${ }^{3)}$, Kenji TSUKANO ${ }^{4)}$, \\ Shin OIKAWA ${ }^{1)}$ and Kazuyuki SUZUKI ${ }^{1) *}$ \\ ${ }^{1)}$ School of Veterinary Medicine, Rakuno Gakuen University, 582 Bunkyodai-Midorimachi, Ebetsu, \\ Hokkaido 069-8501, Japan \\ ${ }^{2)}$ Ehime Agricultural Mutual Aid Association, 4-4-2 Nibancho, Matsuyama, Ehime 790-0002, Japan \\ ${ }^{3)}$ Aichi Agricultural Mutual Aid Association, 2-1-11 Marunouchi, Nakaku, Nagoya 460-0002, Japan \\ 4)Minami-Hokkaido Agricultural Mutual Aid Association, 74-2 Higashimae, Hokuto, Hokkaido 041-1214, Japan
}

J. Vet. Med. Sci.

83(2): 329-332, 2021

doi: 10.1292/jvms.20-0550

Received: 14 September 2020 Accepted: 17 December 2020 Advanced Epub:

29 December 2020
ABSTRACT. This study established the precision and accuracy of a modified latex agglutination turbidimetric immunoassay (LATIA) reagent, and evaluated the ability of the measurement of serum amyloid A (SAA) compared to haptoglobin and a1-acid glycoprotein, which are acute phase proteins (APPs), for diagnosis of clinical mastitis. Concentrations of APPs in cows with mastitis were significantly higher than those in healthy cow. Only the plasma SAA concentration in cows with clinical mastitis $(44.90 \mathrm{mg} / \mathrm{l} ; \mathrm{n}=15)$ was significantly higher than that in those with subclinical mastitis (10.70 mg/l; $n=16)$, enabling their diagnosis in contrast to other APPs. Thus, the SAA assay using a LATIA reagent is useful in assessing mastitis severity due to its higher sensitivity and specificity than other APP assays.

KEY WORDS: acute phase protein, bovine, inflammation, mastitis, serum amyloid A

Bovine mastitis is a major cause of economic loss in the dairy industry [12, 13]. A diagnostic tool for mastitis that is quick and easy to apply is necessary because the severity of inflammation affects the prognosis of cows. A diagnosis of prognosis is important because acute mastitis can be fatal due to severe inflammation. Additionally, subclinical mastitis causes milk losses due to persistent inflammation, but it is difficult to assess the extent of inflammation and subsequent productivity by clinical signs. If an efficient acute phase proteins (APPs) assay is available in bovine practice, the severity of inflammation of mastitis can be estimated.

APPs, such as C-reactive protein (CRP), haptoglobin (HPT), $\alpha 1$-acid glycoprotein (AGP) and serum amyloid A (SAA), are well used as markers to estimate the severity of inflammation in human and companion animal practice $[6,7,15]$. CRP is generally not considered an APP in bovine practice because it does not change due to inflammation in cows [24]. On the other hand, the usefulness of HPT and AGP in the evaluation of inflammation severity was previously reported in bovine mastitis [10].

SAA is clinically applied as an inflammatory marker in horses [23] and cows [4, 14, 19, 21]. SAA responded most rapidly to infection; therefore, the plasma SAA concentration has potential as a marker to distinguish the severity of mastitis [2, 3, 8, 9, 22]. It is known that there are four SAA protein isoforms (SAA1, SAA2, SAA3 and SAA4) in human, and classic proteins for acute phase response is SAA1. Bovine SAA proteins are SAA 1 to 4, like humans, and bovine SAA 1 and 2 are proteins for acute phase response [4].

In bovine SAA assays, the ELISA system is mainly used, but time and cost may be disadvantages of this method for general purposes use as a bovine biomarker. A latex agglutination turbidimetric immunoassay (LATIA) has advantages in that measurement is quick using an automated clinical chemistry analyzer, regardless of the number of samples. When LATIA was applied to cows, a human-specific reagent was used for evaluation of bovine SAA because a cow-specific reagent for the SAA assay using LATIA was not commercially available. However, accurate evaluation of inflammation was difficult because the human-specific reagent was less sensitive for bovine mastitis. Accordingly, a modified reagent for bovine SAA assay using LATIA was prepared for accurate and quick measurement of bovine samples. 
To apply this new reagent in bovine practice, a study comparing SAA measured by the modified reagent with that measured by other APP assays previously validated in cattle is needed. Therefore, the aim of this study was to clarify the usefulness of the modified reagent for bovine SAA, and to evaluate the diagnostic ability of the SAA assay of mastitis in comparison with HPT and AGP.

This animal study was performed in accordance with the Guide for the Care and Use of Laboratory Animals of the School of Veterinary Medicine at Rakuno Gakuen University (Approval\#: VH18C10). Seventy-four Holstein-Friesian lactating cows consisting of 43 healthy and 31 mastitic cows kept at 4 commercial dairy farms in Japan were enrolled in this study. All cows were milked twice daily and fed total mixed rations and provided free access to water.

Blood samples $(10 \mathrm{ml})$ were withdrawn from the jugular vein, and stored in serum separator and heparine-2K-coated vacuum tubes. Serum and plasma were obtained after centrifugation at $1,500 \times \mathrm{g}$ at room temperature for $15 \mathrm{~min}$, and stored at $-80^{\circ} \mathrm{C}$ until assay to avoid repeated thawing and freezing. Refrozen samples were not used in the SAA assay because the SAA concentration is affected by freeze-thaw cycles.

The SAA concentration was measured using an automated LATIA assay kit for animal SAA. This assay kit is a modified human SAA assay kit (LZ test 'Eiken' SAA, Eiken Chemical Co., Tokyo, Japan) and has improved specificity for bovine SAA by changing the antibody. The homologies of amino acid sequences between human SAA 1 and, bovine SAA 1 or 2 is low as the homology are 53.1 or $76.2 \%$. This is due to the deletion of some amino acid sequences in human SAA 1 relative to bovine SAA 1 and 2. However, the homology in other regions is high. In this study, the antibody prepared to targeting the 80th to 90th from the $\mathrm{N}$-terminus of amino acid sequence in the human SAA1 protein and its corresponding amino acid sequences in bovine SAA1 and 2 proteins. Therefore, its accuracy and validation were assessed and performed before the clinical trial. The assay was performed using an automated clinical chemical analyzer (Hitachi 7170S, Hitachi Ltd., Tokyo, Japan) [5].

The detection limit (DL) of the LATIA, which was estimated as the mean \pm 2.6 standard deviation (SD) of SAA determination of blank samples, was $2.90 \mathrm{mg} / \mathrm{l}(P<0.01)$. Linearity under dilution was investigated by linear regression model analysis. The Pearson correlation coefficient was used to assess the strength and direction of association.

Precision was assessed by inter-assay and dilution linearity test. For the inter-assay test, validation was assessed by the coefficient of validation (CV) from the mean and SD of 10 replicate determinations of three pooled bovine sera. The mean SAA concentrations of three bovine sera used in the inter-assay were $11.61,55.83$ and $168.57 \mathrm{mg} / 1$, respectively. The CV ranged from 1.08 to $1.31 \%$.

The dilution linearity test was performed as serial dilutions of two pooled bovine sera, which were diluted to obtain sample volume percentages of 20, 40,60, 80 and 100\%. Expected concentrations of SAA were calculated by dividing the maximum measured value with the modified reagent by the dilution ratio. The mean SAA concentrations of them were $11 \mathrm{and} 158 \mathrm{mg} / \mathrm{l}$. Observed concentrations by the modified SAA assay correlated well with the expected concentration. The regression equations and $r^{2}$ of the two concentration ranges were as follows; $y=0.96 \times-0.45$ and 0.988 , and $y=0.98 \times-8.68$ and 0.979 , respectively.

To evaluate the effects of blood sample types, the correlation of bovine SAA concentration measured by the modified SAA assay between serum and plasma samples was evaluated by linear approximation. Bovine SAA concentrations of serum and plasma samples were well positively correlated. The regression equation and $r^{2}$ were $\mathrm{y}=0.97 \times-0.23$ and 0.992 , respectively, which suggests that both serum and plasma can be used for the measurement and compared. Since plasma samples are generally used in biochemical exams, plasma was used for assays in the study.

Based on the results of the physical examination and modified California Mastitis Test (CMT; P.L tester, Nippon Zenyaku Kogyo Co., Ltd., Fukushima, Japan), cows with and without abnormality were designated as the mastitis group (n=31) and control group $(n=43)$, respectively. The mastitis group was further divided into subclinical $(n=16)$ and clinical mastitis $(n=15)$ groups according to the absence and presence of clinical symptoms such as fever, anorexia, udder swelling, redness and/or hardness [20]. No symptoms suggesting diseases other than mastitis were observed. All cows were examined more than 10 days after parturition and APP levels were not considered to be affected by parturition based on reports of APP levels being higher the week after calving [11].

The milk bacterial test was also carried out for all mastitic milk harvested from cows in the mastitis group in accordance with previously published guidelines [17]. The breakdown of bacteria in each group was as follows: the subclinical group: Staphylococcus aureus (7/16), Streptococcus spp. (3/16), coagulase-negative staphylococci (1/16), Streptococcus uberis (1/16), Corynebacterium bovis (1/16), others (2/16) and not detected (1/16); the clinical mastitis group: Klebsiella pneumoniae (7/15), Escherichia coli (3/15), Trueperella pyogenes (2/15), Streptococcus spp. (1/15), Enterobacter cloacae (1/15) and unknown species (1/15).

As APPs are produced mainly in the liver, blood biochemical tests were carried out to evaluate liver function. The results of blood biochemical tests are summarized in Table 1, with no significant difference between the groups. The plasma HPT (Bovine Haptoglobin ELISA, Immunology Consultants Laboratory, Inc., Portland, OR, USA) and AGP (Bovine $\alpha 1$-glycoprotein ELISA, Immunology Consultants Laboratory, Inc.) concentrations were measured using commercial ELISA kits according to the instructions. The plasma SAA concentration was measured as above.

All statistical analyses were performed by IBM SPSS Statistics, v.23 (IBM Co, Somers, NY, USA). The normally distributed and non-normally distributed data are expressed the means \pm SD and medians [minimum-maximum], respectively. Differences between groups were analyzed with the Mann-Whitney $U$ test. A proposed cut-off value of each APP concentrations to diagnose mastitis was determined using a receiver operating characteristic (ROC) curve. The optimal cut-off point for each APP was calculated by the Youden index $[1,16]$. The significance level was $P<0.05$.

Concentrations of plasma HPT, AGP and SAA in control groups were $0.25[0.10-0.80] \mu \mathrm{g} / \mathrm{ml}, 0.32[0.16-0.72] \mathrm{mg} / \mathrm{ml}$ and 1.00 [0.10-8.00] mg/l, respectively (Table 1). In the mastitis group, APP concentrations were significantly higher than those in control group in plasma HPT $(P<0.001)$, AGP $(P<0.05)$ and SAA $(P<0.001)$. The proposed diagnostic cut-off points for plasma HPT, AGP 
Table 1. Concentrations of acute phase proteins and blood biochemistry in control and mastitis groups

\begin{tabular}{|c|c|c|c|c|c|c|c|c|}
\hline Parameter & Unit & $\begin{array}{l}\text { Control } \\
(\mathrm{n}=43)\end{array}$ & $\begin{array}{c}\text { Mastitis } \\
(\mathrm{n}=31)\end{array}$ & $P$-value & Cut-off value & $\begin{array}{c}\text { Sensitivity } \\
(\%)\end{array}$ & $\begin{array}{c}\text { Specificity } \\
(\%)\end{array}$ & AUC \\
\hline SAA & $(\mathrm{mg} / \mathrm{l})$ & $1.00[0.10-8.00]$ & $20.70[0.80-157.50]$ & $<0.001$ & $6.60 \mathrm{mg} / 1$ & 80.6 & 95.3 & 0.931 \\
\hline HPT & $(\mu \mathrm{g} / \mathrm{ml})$ & $0.25[0.10-0.80]$ & $32.15[0.07-303.25]$ & $<0.001$ & $0.96 \mu \mathrm{g} / \mathrm{ml}$ & 80.6 & 100 & 0.871 \\
\hline AGP & $(\mathrm{mg} / \mathrm{ml})$ & $0.32[0.16-0.72]$ & $0.35[0.18-0.88]$ & 0.019 & $0.34 \mathrm{mg} / \mathrm{ml}$ & 71.0 & 60.5 & 0.661 \\
\hline ALT & $(\mathrm{U} / \mathrm{l})$ & $29.5 \pm 10.2$ & $25.6 \pm 9.9$ & 0.078 & - & - & - & - \\
\hline AST & $(\mathrm{U} / 1)$ & $85.0[52.0-175.0]$ & 7.0 [48.0-204.0] & 0.097 & - & - & - & - \\
\hline$\gamma \mathrm{GTP}$ & (U/1) & $29.0[16.0-60.0]$ & $26.0[14.0-60.0]$ & 0.383 & - & - & - & - \\
\hline BUN & $(\mathrm{mg} / \mathrm{dl})$ & $12.0[6.3-17.2]$ & $13.1[3.7-26.7]$ & 0.095 & - & - & - & - \\
\hline CRE & $(\mathrm{mg} / \mathrm{dl})$ & $0.72[0.55-0.98]$ & $0.73[0.52-1.36]$ & 0.961 & - & - & - & - \\
\hline T-Bil & $(\mathrm{mg} / \mathrm{dl})$ & $0.05[0.00-0.15]$ & $0.05[0.00-1.47]$ & 0.493 & - & - & - & - \\
\hline
\end{tabular}

The normally distributed and non-normally distributed data are expressed the means $\pm \mathrm{SD}$ and medians [minimum-maximum], respectively. SAA: serum amyloid A, HPT: haptoglobin, AGP: $\alpha 1$-acid glycoprotein, ALT: alanine transaminase, AST: aspartate aminotransferase, $\gamma \mathrm{GTP}: \gamma$-glutamyltransferase, BUN: blood urea nitrogen, CRE: creatinin, T-Bil: total bilirubin, AUC: area under the curve.

and SAA concentrations to identify dairy cattle with mastitis based on analyses of ROC curves were set at $>0.96 \mu \mathrm{g} / \mathrm{ml},>0.34 \mathrm{mg} /$ $\mathrm{ml}$ and $>6.60 \mathrm{mg} / \mathrm{l}$, respectively. All APPs were able to diagnose mastitis. The reason for the significant changing in APPs values despite the unchanged biochemical test results were considered to be due to the lack of strong systemic inflammation of mastitic cattle used in this study.

The plasma SAA concentration was significantly higher in the clinical group (44.90 [7.40-157.50] mg/l) than in the subclinical group $(10.70$ [0.80-59.90] mg/1, $P<0.001$, Fig. 1A), although no significant differences between subclinical and clinical groups were observed in plasma HPT and AGP concentrations. The proposed diagnostic cut-off point for plasma SAA concentrations to identify dairy cattle with clinical mastitis based on analyses of ROC curves was set at $>14.05 \mathrm{mg} / 1$ (Fig. 1B). The results of this study are consistent with a previous study using an ELISA system to demonstrate significant differences in the blood SAA level by severity of inflammation [18].

In the present study, plasma HPT, AGP and SAA concentrations in cows with mastitis were significantly higher than those in healthy cows, and these APP levels reflect inflammation caused by mastitis. Furthermore, the plasma SAA concentration was able to distinguish subclinical and clinical mastitis. Thus, the plasma SAA concentration using a modified reagent for animals was superior in assessing the severity of inflammation in mastitis due to its higher sensitivity and specificity than other APP assays.

A

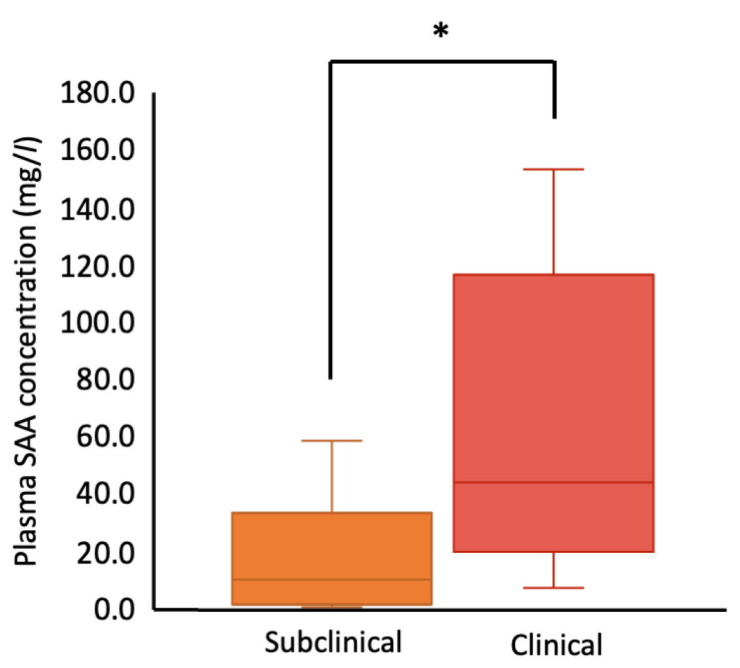

B

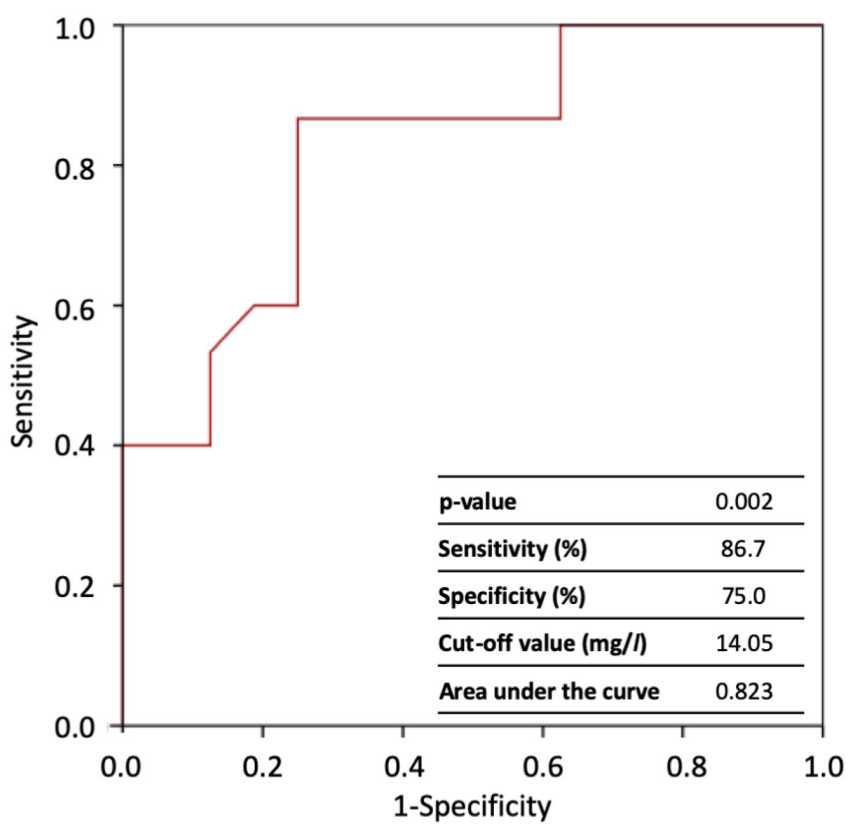

Fig. 1. Comparison of serum amyloid A (SAA) concentrations of subclinical and clinical mastitis groups. A: The plasma SAA concentration in the subclinical and clinical groups. The horizontal line in each box represents the median value. The boxes represent the interquartile range (25 to 75 percentiles). *Values with asterisks are significantly different between groups $(P<0.05)$. B: The receiver operating characteristic $($ ROC) curves of the plasma SAA concentration to identify dairy cattle with clinical mastitis. 
Therefore, the plasma SAA concentration measured by LATIA is useful to asses bovine mastitis quickly and accurately than other APP assays. Furthermore, the plasma SAA concentration measured by the present LATIA may assist in assessing the outcomes of cows with mastitis.

POTENTIAL CONFLICTS OF INTEREST. The authors have nothing to disclose.

ACKNOWLEDGMENTS. We thank Dr. Kikuchi, T., Dr. Asahi, Y. and Dr. Inamori, S. for support in the measurement of SAA.

\section{REFERENCES}

1. Akobeng, A. K. 2007. Understanding diagnostic tests 3: Receiver operating characteristic curves. Acta Paediatr. 96: 644-647. [Medline] [CrossRef]

2. Alsemgeest, S. P., Kalsbeek, H. C., Wensing, T., Koeman, J. P., van Ederen, A. M. and Gruys, E. 1994. Concentrations of serum amyloid-A (SAA) and haptoglobin (HP) as parameters of inflammatory diseases in cattle. Vet. Q. 16: 21-23. [Medline] [CrossRef]

3. Boosman, R., Niewold, T. A., Mutsaers, C. W. and Gruys, E. 1989. Serum amyloid A concentrations in cows given endotoxin as an acute-phase stimulant. Am. J. Vet. Res. 50: 1690-1694. [Medline]

4. Ceciliani, F., Ceron, J. J., Eckersall, P. D. and Sauerwein, H. 2012. Acute phase proteins in ruminants. J. Proteomics 75: 4207-4231. [Medline] [CrossRef]

5. Christensen, M., Jacobsen, S., Ichiyanagi, T. and Kjelgaard-Hansen, M. 2012. Evaluation of an automated assay based on monoclonal anti-human serum amyloid A (SAA) antibodies for measurement of canine, feline, and equine SAA. Vet. J. 194: 332-337. [Medline] [CrossRef]

6. Cray, C., Zaias, J. and Altman, N. H. 2009. Acute phase response in animals: a review. Comp. Med. 59: 517-526. [Medline]

7. Eckersall, P. D. and Bell, R. 2010. Acute phase proteins: Biomarkers of infection and inflammation in veterinary medicine. Vet. J. 185: $23-27$. [Medline] [CrossRef]

8. Heegaard, P. M., Godson, D. L., Toussaint, M. J., Tjørnehøj, K., Larsen, L. E., Viuff, B. and Rønsholt, L. 2000. The acute phase response of haptoglobin and serum amyloid A (SAA) in cattle undergoing experimental infection with bovine respiratory syncytial virus. Vet. Immunol. Immunopathol. 77: 151-159. [Medline] [CrossRef]

9. Horadagoda, A., Eckersall, P. D., Hodgson, J. C., Gibbs, H. A. and Moon, G. M. 1994. Immediate responses in serum TNF $\alpha$ and acute phase protein concentrations to infection with Pasteurella haemolytica A1 in calves. Res. Vet. Sci. 57: 129-132. [Medline] [CrossRef]

10. Horadagoda, N. U., Knox, K. M. G., Gibbs, H. A., Reid, S. W. J., Horadagoda, A., Edwards, S. E. R. and Eckersall, P. D. 1999. Acute phase proteins in cattle: discrimination between acute and chronic inflammation. Vet. Rec. 144: 437-441. [Medline] [CrossRef]

11. Humblet, M. F., Guyot, H., Boudry, B., Mbayahi, F., Hanzen, C., Rollin, F. and Godeau, J. M. 2006. Relationship between haptoglobin, serum amyloid A, and clinical status in a survey of dairy herds during a 6-month period. Vet. Clin. Pathol. 35: 188-193. [Medline] [CrossRef]

12. Kandasamy, S., Green, B. B., Benjamin, A. L. and Kerr, D. E. 2011. Between-cow variation in dermal fibroblast response to lipopolysaccharide reflected in resolution of inflammation during Escherichia coli mastitis. J. Dairy Sci. 94: 5963-5975. [Medline] [CrossRef]

13. Kerro Dego, O., Oliver, S. P. and Almeida, R. A. 2012. Host-pathogen gene expression profiles during infection of primary bovine mammary epithelial cells with Escherichia coli strains associated with acute or persistent bovine mastitis. Vet. Microbiol. 155: 291-297. [Medline] [CrossRef]

14. Lehtolainen, T., Røntved, C. and Pyörälä, S. 2004. Serum amyloid A and TNF $\alpha$ in serum and milk during experimental endotoxin mastitis. Vet. Res. 35: 651-659. [Medline] [CrossRef]

15. Murata, H., Shimada, N. and Yoshioka, M. 2004. Current research on acute phase proteins in veterinary diagnosis: an overview. Vet. J. 168: 28-40. [Medline] [CrossRef]

16. Nakas, C. T., Dalrymple-Alford, J. C., Anderson, T. J. and Alonzo, T. A. 2013. Generalization of Youden index for multiple-class classification problems applied to the assessment of externally validated cognition in Parkinson disease screening. Stat. Med. 32: 995-1003. [Medline] [CrossRef]

17. National Mastitis Council. 2017. Laboratory handbook on bovine mastitis, 3rd ed. National mastitis Council, New Prague.

18. Nazifi, S., Haghkhah, M., Asadi, Z., Ansari-Lari, M., Tabandeh, M. R., Esmailnezhad, Z. and Aghamiri, M. 2011. Evaluation of Sialic Acid and Acute Phase Proteins (Haptoglobin and Serum Amyloid A) in Clinical and Subclinical Bovine Mastitis. Pak. Vet. J. 31: $353-358$.

19. Nielsen, B. H., Jacobsen, S., Andersen, P. H., Niewold, T. A. and Heegaard, P. M. H. 2004. Acute phase protein concentrations in serum and milk from healthy cows, cows with clinical mastitis and cows with extramammary inflammatory conditions. Vet. Rec. 154: 361-365. [Medline] [CrossRef]

20. Ruegg, P. L. and Erskine, R. J. 2020. Mammary gland health and disorders. pp. 1118-1150. In: Large Animal Internal Medicine, sixth ed. (Smith, B. P., Van Metre, D. C., Pusterla, N. eds.), Elsevier, St. Louis.

21. Thomas, F. C., Geraghty, T., Simões, P. B. A., Mshelbwala, F. M., Haining, H. and Eckersall, P. D. 2018. A pilot study of acute phase proteins as indicators of bovine mastitis caused by different pathogens. Res. Vet. Sci. 119: 176-181. [Medline] [CrossRef]

22. Werling, D., Sutter, F., Arnold, M., Kun, G., Tooten, P. C., Gruys, E., Kreuzer, M. and Langhans, W. 1996. Characterisation of the acute phase response of heifers to a prolonged low dose infusion of lipopolysaccharide. Res. Vet. Sci. 61: 252-257. [Medline] [CrossRef]

23. Witkowska-Piłaszewicz, O. D., Żmigrodzka, M., Winnicka, A., Miśkiewicz, A., Strzelec, K. and Cywińska, A. 2019. Serum amyloid A in equine health and disease. Equine Vet. J. 51: 293-298. [Medline] [CrossRef]

24. Yogeshpriya, S. and Selvaraj, P. 2019. C-Reactive Protein in Veterinary Practice. Dairy and Vet. Sci. J. 13: 555858. 